\title{
Modos narrativos de fazer mundos: jornalismo, ficção e verdade
}

\section{Narrative ways of world making: journalism, fiction and truth}

\author{
Antonio Claudio Engelke Menezes Teixeira \\ Mestre e Doutor em Ciências Sociais pela PUC-Rio, realiza pós-doutorado no Departamento de Ciência Política da Universidade \\ Estadual do Rio de Janeiro (UERJ).
}

<antonioengelke@gmail.com>

\section{RESUMO}

Os autores que avançaram a noção construtivista da notícia como uma narrativa permaneceram presos ao paradigma do jornalismo como espelho da realidade. A alternativa aqui proposta consiste em radicalizar a perspectiva do jornalismo como atividade poética de criação de mundos. Para tanto, será preciso abandonar o mito da objetividade e solapar a primazia da noção de verdade como correspondência com a realidade, sem, contudo, cair no relativismo. Trata-se de deslocar o critério empregado para decidir sobre a validade do discurso jornalístico: não mais o objetivismo, que insiste na fidelidade aos "fatos"tais como supostamente ocorreram, mas uma hermenêutica atenta à fertilidade das perspectivas que as narrativas jornalísticas trazem à esfera pública.

\begin{abstract}
Despite their efforts, authors who put forward the constructivist notion of news as narratives remained trapped within the paradigm of journalism as a mirror of reality. The alternative developed here aims to radicalize the idea of journalism as poetic activity of world making. To do so, we must first abandon the myth of objectivity and dislodge the primacy of the notion of truth as correspondence with reality, without falling through the slippery slope of relativism. We shall propose other criteria for grounding the validity of journalistic discourse: no longer the objectivist view that insists on getting the "facts" as they allegedly happened, but an hermeneutic approach that reflects upon the fertility of the perspectives newspapers brings to the public sphere.
\end{abstract}

\begin{abstract}
Keywords: Journalism. Narratives. Relativism.
O real precisa ser ficcionado para ser pensado.
\end{abstract} (Ranciére, 2009, p.58.)

\section{Introdução}

As críticas ao jornalismo, seja ao nível da agência individual, da organização institucional ou dos constrangimentos sistêmicos, procuram expor a dinâmica de seus "bastidores" no intuito de revelar o que se sucede no "palco". As metodologias diferem, assim como os diagnósticos obtidos, mas a inspiração é bastante semelhante. Ao olharmos para o jornalista tomado isoladamente, seu trabalho diário nas redações, encontramos um sujeito que seleciona 
arbitrariamente o conteúdo a ser publicado, assim desempenhando a função de gatekeeper (White, 1999). Estendendo o escopo da observação, vê-se que a decisão acerca do que conta como notícia depende não apenas de avaliações idiossincráticas de repórteres e editores, mas sobretudo da estrutura burocrática das organizações que lhes pagam o salário (Breed, 1999).

Se, dando sequência ao movimento, ampliarmos o horizonte da crítica de modo a abarcar os condicionantes estruturais do campo jornalístico, bem como suas implicações sociais e políticas, abriremos um leque de análises que abrangem desde o exame da mídia na conformação da esfera pública, condição indispensável à formação de consensos, dos quais uma democracia não pode prescindir se quiser funcionar adequadamente (Habermas, 1997), até a denúncia do jornalismo como operador da reprodução dos interesses dominantes (Chomski, 2003). Diversificaram-se, neste percurso, as ferramentas heurísticas e as perspectivas a que estas dão ensejo: o estruturalismo de cunho marxista subjacente ao estudo da economia política das grandes empresas de mídia e dos efeitos ideológicos de sua atuação (Bourdieu, 1997); a ênfase culturalista na notícia como um construto social e a analítica do discurso feita a partir das noções de framing (Kuypers, 2010) e agenda-setting (McCombs, 2004); e, mais recentemente, os chamados estudos de recepção que, importando reflexões oriundas da teoria literária, deslocam a visão da mídia como indústria monolítica de fabricação de consciência, compreendendo-a como um ator contraditório dentro de um campo em permanente disputa (Motta, 2005c).

Fugiria completamente ao escopo deste artigo fazer um resumo da análise sociopolítica do jornalismo, tarefa ademais já realizada com a devida competência (Traquina, 2012). Mas talvez seja salutar retomar alguns de seus pontos, agora que o gradual abandono do modelo liberal de jornalismo (o padrão catch-all) em favor de estratégias editoriais assumidamente partidárias, somado à perda do monopólio da significação dos eventos por parte da mídia corporativa, reacenderam o debate acerca do compromisso da atividade jornalística com os ideais de objetividade e neutralidade.

Não é intuito deste artigo discutir as causas recentes deste movimento, como a redução dos custos de produção de informação em função das novas tecnologias de comunicação, o aumento da oferta de entretenimento via TV a cabo e a consolidação da lógica de nicho favorecida pela internet; limitome somente a observar que a atual tendência à polarização política dos grandes veículos de comunicação explica-se sobretudo em função de tais constrangimentos mercadológicos (Albuquerque, Lycarião e Magalhães, 2015). Pressionados por forças de mercado, jornais e revistas encontram-se cada vez 
mais impelidos a apostar num modelo politicamente engajado ou advocatício de produção de informação, assim deslocando os marcos normativos canônicos da práxis jornalística.

O declínio da força de tais marcos normativos, contudo, tem já uma história, iniciada com a vaga antipositivista que varreu o mundo a partir dos anos 60. $\mathrm{O}$ ataque se deu em diferentes frentes e níveis de argumentação: no plano filosófico, a desconstrução pós-moderna da ideia de verdade como correspondência com a realidade implicando no questionamento acerca da natureza textual das representações; no registro mais empírico, a norma da objetividade sendo concebida ora como um "ritual estratégico" utilizado para posicionar-se diante do público e de outros colegas (Tuchman, 1972), ora como expediente mercadológico que permite aos veículos de comunicação apresentarem-se como neutros e imparciais (Ognaniova e Endersby, 1996); por fim, mas não menos importante, a crítica endógena ao próprio campo do jornalismo, o questionamento advindo do trabalho de correspondentes de guerra, apanhados no dilema de permanecerem fiéis à neutralidade professada, mas ao preço de tornarem-se em alguma medida cúmplices das atrocidades testemunhadas. Antes da virada para o século XX o criticismo outrora marginal começaria a ganhar ares de nova ortodoxia - na década de 1990, a norteamericana Society of Professional Journalism retirava o termo "objetividade" de seu código de ética (Calcutt e Hammond, 2011).

As tentativas de incorporar tais críticas ao pensamento acerca da objetividade jornalística, expressas em propostas como a exigência da transparência de posicionamento ideológico do jornal, a chamada epistemologia posicional eo ideal bakhtiniano de um jornalismo polifônico, têm se mostrado até aqui insuficientes. Senão, vejamos. Reconhecidas a distância entre objetividade e certeza, e a impossibilidade de blindar o texto jornalístico dos valores de seus escribas (e das empresas para as quais trabalham), seria então o caso de explicitá-los, torná-los transparentes, o que permitiria ao consumidor fazer uma leitura mais informada, ou menos ingênua, das notícias ofertadas (Boudana, 2011). Em que pese a correção que introduz, proveitosa sob qualquer ângulo, tal movimento não resolve o problema. Declarar-se republicano ou democrata, Partido dos Trabalhadores (PT) ou Partido da Social Democracia Brasileira (PSDB), não dá ao leitor condições para avaliar os pressupostos sobre os quais os enquadramentos de todas as notícias, e não somente aquelas referidas exclusivamente ao jogo eleitoral, são construídos. O adensamento dessa proposta, expresso na adoção de uma epistemologia posicional (standpoint epistemology), também não parece oferecer solução satisfatória. Inspirada na 
teorização feminista, a epistemologia posicional sugere oferecer um modo concreto de maximizar o papel da reflexividade na reportagem, reduzindo sua dependência das consciências morais individuais, priorizando o uso da natureza socialmente situada das alegações de verdade dos atores envolvidos nas notícias (Durham, 1998).

Se reportagens fossem escritas desde a perspectiva dos sujeitos cujas vidas são mais impactadas pelos eventos relatados, haveria um contrabalanceamento em relação à posição dominante do jornalista como insider, produzindo uma operacionalização daquilo que Gans (1979) chamou de "notícias multiperspectivadas", um método que adicionaria uma visão horizontal à prática verticalizada da produção jornalística. Mais ainda, o fato de o texto vir banhado em uma sensibilidade multicultural já constituiria um desafio ao entendimento tradicional de objetividade, pois que implicaria no abandono do binarismo algo hipócrita de "ouvir ambos os lados", substituindo-o por uma leitura realmente compromissada com a apresentação dos fatos em sua pluralidade de perspectivas (Deuze, 2005, p. 456). Mas a despeito de sua fertilidade normativa, é difícil imaginar como tal proposta poderia efetivamente ser colocada em prática por atores da mídia tradicional.

Abstraídos os entraves mercadológicos e ideológicos que o jornalista multiperspectivista enfrentaria, permanecem ainda assim as restrições incontornáveis do tempo e do espaço, necessários à problematização da natureza de sua própria produção textual. A complexidade de uma polifonia bakhtiniana, ou a sensibilidade exigida para colocar-se em posição de falar com os objetos de reportagens, e não sobre eles, não cabem nem nas poucas linhas de um texto de jornal, nem nos prazos usualmente delimitados para redigi-lo. Nessas circunstâncias, o virtuosismo exigido numa montagem efetivamente polifônica das vozes no texto jornalístico não seria, na contramão de sua inspiração original, indício de sua manipulação por parte de um único autor?

Feito este preâmbulo, eis a situação atual. No cotidiano das redações, cresce a pressão no sentido de adotar partidarismos políticos; sua expressão, no entanto, permanece dissimulada, raramente vindo acompanhada de admissão explícita'. Na esfera pública cada vez mais conectada em rede, a circulação de narrativas alternativas às da mídia corporativa, ainda que em forma embrionária e de alcance bastante limitado, deflagraram uma onda de contestação quanto ao que é percebido como uma afronta aos princípios éticos do jornalismo.

1 Dos grandes veículos de comunicação brasileiros, apenas o Estadão declara abertamente seu apoio a candidatos. 
Na Academia, estudiosos da relação entre comunicação e política parecem crescentemente dispostos a explorar, por meio de análises de enquadramento cada vez mais sofisticadas, inclusive com o emprego de algoritmos matemáticos e softwares de análise de sentimento, o substrato ideológico das representações que o jornalismo traz a público; não será coincidência o recurso frequente ao conceito de valência, que procura estabelecer uma base supostamente empírica para a aferição das simpatias ou antipatias partidárias². Tudo isso faz crer que o debate sobre jornalismo e ideologia recrudesceu uma vez mais, suscitando nova oportunidade de apreciá-lo.

No que se segue, procuro observar alguns impasses da crítica ideológica da grande mídia, sugerindo como alternativa teórica mais profícua a retomada da perspectiva construcionista centrada na noção de notícia como narrativa. Com o auxílio da filosofia analítica da linguagem e da problematização da textualidade no discurso historiográfico, pretendo radicalizar tal perspectiva, e argumentar que o critério de validade do discurso jornalístico não pode se prender única ou primordialmente ao referente empírico, devendo, ao contrário, radicar-se num esforço de interpretação acerca dos mundos que esse discurso ajuda a construir. Por fim, busco contornar a principal objeção tradicionalmente feita à visão que proponho, a de que o abandono da primazia das noções de imparcialidade e correspondência à realidade redunda num relativismo que condena o jornalismo à vala comum da propaganda ideologicamente compromissada.

\section{Contradições da crítica à ideologia no jornalismo}

Elencar os atributos que demarcariam a aptidão de um fato para converterse em notícia, perguntando pelas características e processos que confirmam sua "noticiabilidade" (Wolff, 1990), é apenas descrever procedimentos do campo jornalístico, como se naturais fossem; nada nos diz sobre os pressupostos e efeitos de tal operação. Melhor seria observar que, mais que mero suporte, o jornal está inserido num dispositivo mais amplo de informação, uma matriz cuja existência é anterior ao texto, que implica num modo de estruturação próprio e "prepara para o sentido" (Mouillaud, 2012, p. 48). Trata-se de examinar como as escolhas feitas acabam por conformar uma determinada estória, e o que as exclusões e omissões necessárias à sua feitura poderiam revelar sobre as estórias que não chegaram a ser contadas. Contudo, assim como o esquecimento

2 Disponível em: $<$ www.manchetometro.com.br $>$. Para uma crítica ao conceito de valência, ver Miguel, 2015. 
não é o contrário da memória, mas sua condição de possibilidade, também o recorte e a hierarquização de informações são necessários à atividade de leválas ao conhecimento público por meio de veículos de comunicação. Dada a impossibilidade de abarcar a totalidade dos fatos, limitação inerente a qualquer atividade descritiva, a omissão e o esquecimento operados pela mídia são, em princípio, um imperativo inescapável da atividade jornalística, não um investimento ideológico. Mas a frequência com que o imperativo desliza para o investimento, e os contornos que tais deslizamentos assumem, autorizam a hipótese de que se tratam de irrupções sintomáticas que traduzem os interesses comerciais e políticos dos grandes conglomerados de mídia, e que justamente por isso não podem ser expressos enquanto tais.

As objeções levantadas ao determinismo econômico, sempre disposto a reduzir a ação política do jornalismo à mera função de reprodutor da ideologia hegemônica burguesa, são bem conhecidas, e não será o caso de retomá-las aqui em seus aspectos substantivos (Traquina, 2012). Contudo, visto o recente aquecimento de denúncias e estudos acerca dos compromissos ideológicos da mídia corporativa, talvez haja alguma utilidade em retomar a questão desde o ponto de vista de suas contradições formais.

Criticar o jornalismo por falhar em ser objetivo e, ao mesmo tempo, afirmar a impossibilidade da própria noção de objetividade, é operação logicamente inconsistente (Lichtenberg, 1991). Ademais, apontar a parcialidadede manchetes e reportagens pode até ser politicamente saudável, mas, paradoxalmente, fortalece o vocabulário que pretende erodir, pois que criticar um jornal pelo viés de suas representações é assumir como dada a possibilidade de desempenhar a tarefa de forma não distorcida, referendando os pressupostos normativos que jazem na base do fetiche da objetividade. O problema, evidentemente, não está em analisar o discurso jornalístico no intuito de lhe revelar as tendências ocultas e os mecanismos de funcionamento, mas sim em assumir que isto deva ser feito contra o pano de fundo do referente ao qual ele deveria obediência - os "fatos".

A despeito de suas contribuições, as versões mais sofisticadas da crítica à parcialidade, centradas não na coloração ideológica de um ou outro jornal, mas na própria operação de retalho da realidade, feita no intuito de apresentála, e no déficit cognitivo a que dá ensejo, não se saem muito melhor nesse quesito. Bourdieu resumiu bem o ponto, notando as afinidades eletivas entre o predomínio do fait divers e outros aspectos estruturais da imprensa, como a "circulação circular da informação", a lógica da concorrência operando a homogeneização da produção jornalística, e a tendência a privilegiar descrições feitas por sobre ideias cuja aceitação esteja garantida, de modo a evitar possíveis 
ruídos de recepção (Bourdieu, 1997, p. 30-38). Some-se a isso a lógica do espetáculo, a presentificação atomista que impede a compreensão nuançada de eventos, o personalismo voyeurístico, a obsessão por descrever a vida política sob uma ótica degradada até o ponto da estereotipagem (Patterson, 1993), e o que parece emergir é a consolidação do escândalo como linguagem do noticiário, o desencanto seguindo-se à despolitização.

Fixada a chave cognitiva que obstaculiza o exercício de compreender e situar fatos dentro de enquadramentos que os contextualizem adequadamente (Coelho, 2007), os consumidores de informação cairiam vítimas de uma espécie de "amnésia estrutural". É a própria inteligibilidade do real que está em jogo, e este vácuo narrativo que conjuga a lógica espetacularizada do fait divers com uma hiperfactualidade persecutória e iconoclasta poderia ser visto como um sintoma do vazio das metanarrativas. Tudo, somado, tem-se a impressão de que se repórteres e editores fossem pós-graduados em ciências sociais, se moldassem, portanto, seu trabalho em consonância com as críticas que lhes são endereçadas, o jornalismo estaria, enfim, mais próximo de cumprir sua missão de apresentar "os fatos".

Pode-se eventualmente concordar com tais objeções, e, ainda assim, interrogar seu papel na própria reprodução da autoimagem de jornalistas. Cabe a pergunta: e se ser visto como produtor de instantâneos factuais a-históricos for algo desejável para o campo do jornalismo, desde o ponto de vista de sua justificação ideológica? Dito de outro modo, o fato de ser publicamente reconhecido como denunciante de escândalos e relator de fait divers esparsos, e não como produtor de narrativas, não será justamente um dos ingredientes indispensáveis ao trabalho ideológico do jornalismo, no sentido de contar com o salvo-conduto da objetividade? Se tivermos em mente que o fetiche da objetividade é ingrediente fundamental à reivindicação de credibilidade, da qual depende a manutenção do capital simbólico de jornais e jornalistas, e se lembrarmos ainda que a ideia de "narrativa" encontra-se num campo semântico povoado por noções de forte coloração subjetivista, como "história", "enredo" e "personagem", então não será ilícito concluir que esta denúncia do jornalismo como operador da acronia e atopia, por mais válida que seja, acaba contribuindo inadvertidamente para manter despercebida uma característica fundamental do fazer jornalístico, qual seja, o caráter poético de sua operação narrativa.

Eis a verdade que o jornalismo precisa recalcar para se manter enquanto tal: redações de grandes veículos podem sobreviver razoavelmente incólumes à acusação de que promovem amnésia estrutural ou recortes mal-ajambrados da realidade, mas não à percepção generalizada de que produzem, a partir 
de artefatos verbais, narrativas tão próximas de ficções literárias quanto de descrições factuais. Quem constrói narrativas dificilmente poderá se fazer aceito como imparcial ou objetivo, pois que todo contar de história implica na assunção de uma perspectiva, de um narrador; quem, por outro lado, é visto (e vê a si próprio) como mero recolhedor e apresentador de fatos diversos, isolados, encontra mais facilidade para cobrir-se com o manto protetor da imparcialidade.

Ao fim e ao cabo, o criticismo que visa desmascarar as simpatias ocultas do jornalismo, geralmente fundado na certeza do compadrio ideológico ex ante facto, não apenas vicia na origem os diagnósticos que produz, como ainda reforça o vocabulário que pretende combater. Se quisermos uma alternativa de maior rendimento crítico, a concepção de notícia como uma narrativa parece melhor candidata. Claro está que a reflexão acerca do caráter poético da produção jornalística não é novidade; já em 1925 Robert Park dizia ser a notícia de jornal uma forma de literatura popular. Mas foi somente nos anos 1970, a partir da consolidação do paradigma construcionista de crítica ao jornalismo ${ }^{3}$, oposto tanto à perspectiva da notícia como distorção ideologicamente motivada, quanto à da notícia como espelho da realidade, que tal crítica ganhou fôlego (Traquina, 2012). Ancorados na compreensão de que a linguagem não é um meio transparente de representação da realidade, mas uma ferramenta da qual dispomos para lidar com ela, os autores "narrativistas" procuraram avançar a reflexão sobre o caráter poético da produção jornalística, pensando-a como um gênero literário ou um tipo particular de narrativa mitológica (Bird e Dardenne, 1999). Nessa perspectiva, "o jornalismo não é ficção, mas é narrativa; como narrativa, pode ser interpretado como ficção" (Motta, 2005a, p. 25).

As fronteiras epistemológicas tradicionais estipulam que o jornalismo é regido pela convenção da veracidade, ao passo que narrativas literárias atendem a convenções de ficcionalidade, e que, ao contrário do escritor de ficção, o jornalista tem pretensão de verdade, precisa ajustar-se ao mundo real, descrevendo-o tanto quanto possível (Sanchez, 1992). É bem verdade que construcionistas em geral, e "narrativistas" em particular, ajudaram a borrar tais fronteiras, mas o fizeram com tamanha reverência à distinção entre fato e valor, que caberia perguntar se conseguem efetivamente extrair todo o rendimento da perspectiva que propõem. "Considerar as notícias como narrativas”, afirmam

3 O paradigma construcionista abriga autores de correntes diversas, como a estruturalista e a interacionista. Uso o neologismo "narrativistas" para me referir a um subconjunto específico de autores deste paradigma, que partilham o intuito de avançar a crítica pela via da observação da natureza textual do jornalismo. 
Bird e Dardenne (1999, p. 265), "não nega o valor de as considerar como correspondentes da realidade exterior". Gaye Tuchman sugere que "dizer que uma notícia é uma 'estória' não é de modo algum rebaixar a notícia, nem a acusar de ser fictícia. Melhor, alerta-nos para o facto de a notícia [...] ser uma realidade construída possuidora da sua própria validade interna" (1999, p. 262; grifo nosso). Mais recentemente, a absorção das teorias da recepção pelo campo dos media studies adicionou um novo elemento a esta equação. A narratividade deixa de ser unicamente propriedade intrínseca ao texto jornalístico, referida ao estilo de escrita ou modo de composição da notícia, dado que "é o leitor ou ouvinte, no ato de recepção das notícias, que conclui a obra" (Motta, 2005b, p. 9). Em resumo, segundo o paradigma narrativista, notícias são construções literárias, e não meros reflexos descritivos; possuem sua própria validade interna, mas não são artefatos acabados em si mesmos, pois que sua significação depende também do modo como são lidas e interpretadas; ao mesmo tempo, conservam seu valor na medida em que correspondam à realidade.

Os autores "narrativistas" apenas arranharam a superfície do objetivismo que pretendiam deslocar, pois que permaneceram presos à noção da verdade como correspondência da realidade que jaz na base do tradicional paradigma do jornalismo como espelho de fatos. Mas ou ambos caem juntos, ou permanecem de pé; não é possível ultrapassar tal paradigma sem abandonar a noção de verdade como correspondência à realidade. Radicalizar o entendimento do jornalismo como um empreendimento fundamentalmente literário implicará em lidar com duas ordens de problemas: a necessidade de postular um critério para decidir o que conta como bom ou mau jornalismo, critério este que não esteja atrelado umbilicalmente ao referente empírico da notícia, e a necessidade de responder às acusações de se estar assumindo uma posição relativista, algo que inevitavelmente incide sobre todos aqueles que realizam o tipo de movimento aqui proposto.

\section{Radicalizar a notícia como narrativa}

O jornalismo é o único campo produtor de conhecimento que parece haver passado incólume pela virada linguística; talvez por esta razão possa ser considerado o modo hegemônico de ficção a partir de meados do século XX. Ao contrário de cientistas sociais, jornalistas não precisam explicitar as condições de produção de seu trabalho; basta que se mantenham apegados a uma linguagem supostamente descritiva, e que observem o imperativo da pluralidade de fontes. Esforçam-se o quanto podem para neutralizar "as marcas enunciativas, evitando o uso das formas indexicais, dos dispositivos de linguagem que explicitam a 
relação dos enunciados com a pessoa, o lugar e o tempo da própria enunciação" (Rodrigues, 2012, p. 240), e seguem trabalhando como se a distinção entre fato e valor fosse verdade autoevidente. "O jornalismo procura representar a realidade dos fatos, operando, assim, uma virtualização da realidade, sem, contudo, ficcioná-la" (Silva, 2012, p. 344-345) - eis a ilustração perfeita do verniz ideológico de que o jornalista necessita para continuar acreditando na correção ética do próprio trabalho. Tal definição evita o ranço positivista, isto é, reconhece que qualquer representação do real é necessariamente falha (daí a operação de "virtualização" da realidade), ao mesmo tempo em que procura manter os pés fincados no realismo, querendo com isso escapar ao fantasma da ficção.

O fantasma, no entanto, é real. O refluxo da onda linguística pós-moderna implicou no "retorno do referente", a busca por uma ancoragem para nossas alegações de conhecimento. Mas esse retorno não pode mais ser empreendido de modo ingênuo, isto é, não pode desprezar toda a teorização acerca dos modos de pensar como a linguagem se prende à realidade (Hutcheon, 1991). Se, como dizia Paul Veyne (1971), o acontecimento só pode ser conhecido por meio de seus vestígios, então nada mais lícito do que perguntar pela natureza do referente no discurso jornalístico - seria o acontecimento, o vestígio textualizado ou a experiência pessoal do jornalista? Mais ainda, se a única maneira de identificar um fato é através do vocabulário dentro do qual nossas crenças são formuladas, e se o evento-em-si não se solidifica por conta própria na forma de sentenças descritivas (Rorty, 1994), então por que motivo deveríamos continuar dando primazia à avaliação de notícias como correspondentes da realidade exterior?

Nenhum acontecimento constitui por si só uma história acabada, apenas oferece elementos a partir dos quais se pode tecer sua trama (White, 2008). Nesse sentido, afirmar que a significação dos eventos nunca está dada é dizer que eles não nos impõem vocabulários ou perspectivas através das quais deveríamos obrigatoriamente narrá-los. Dito de outro modo, o evento-emsi condiciona, mas não fundamenta, nosso conhecimento acerca dele, o que é apenas uma maneira de recolocar (mas em outro registro) a tese de Wilfrid Sellars (2008) de que a experiência ou a sensação não podem servir como fundamento para o conhecimento; seriam, no máximo, uma condição para o conhecimento. Segundo Sellars, há dois tipos de percepção: "comportamento discriminativo", que é apenas o fato bruto de sentir fome ou frio, por exemplo, e "estar no espaço lógico das discriminações", que implica em saber qual o tipo de sensação se está experimentando. O comportamento meramente discriminativo dispensa o uso de palavras, pois que não precisamos ter acesso a uma linguagem para saber o que é sentir fome ou frio. "Estar no espaço lógico 
das discriminações", ao contrário, supõe o recurso à linguagem, pois saber que tipo de coisa é - $x$ - requer o acesso a um vocabulário adequado, que permite apreender o conceito de $x$ e fazer afirmações a seu respeito. Estes dois tipos de percepção, embora intimamente relacionados, são de naturezas diferentes. Sensações pré-linguísticas não poderiam servir de fundamento para o sentido, haja visto que não seria razoável buscar em fatos não linguísticos o fundamento para fatos linguísticos. Aquilo a que chamamos de sentido só emerge quando entramos no espaço lógico das justificações, quando utilizamos recursos que estão no domínio da linguagem. Transportando o raciocínio de volta ao objeto deste artigo, seria o caso de dizer que o sentido de um relato jornalístico não se desprende naturalmente dos acontecimentos, como o vapor da água; é lhes acrescido pelo jornalista à medida em que transforma sua compreensão do que se passou em relatos que pretendem narrá-los.

Os tipos específicos de histórias não estão incrustados no evento-emsi. São impostos por quem os narra através de uma dupla operação poética, cognitiva e expressiva, ambas tropológicas. "Antes que um dado domínio possa ser interpretado, há de ser primeiro organizado como um território povoado por figuras discerníveis", ou seja, a experiência deve primeiramente ser constituída como objeto de percepção mental, deve ser prefigurada num "nível profundo de consciência" do narrador (White, 2008, p. 44-45). Este é um ato fundamentalmente poético, pré-crítico, no qual o historiador - e também o jornalista - cria seu objeto de análise no processo de reconhecê-lo, ao mesmo tempo em que predetermina a modalidade das estratégias narrativas das quais se valerá posteriormente em sua descrição. "O pensamento", escreve Hayden White, "permanece cativo do modo linguístico no qual procura apreender o contorno dos objetos que povoam seu campo de percepção" (White, 2008, p. 14). Se, por exemplo, ao narrar um evento, o historiador lhe confere a estrutura de enredo de uma tragédia, então ele o terá "explicado" desta maneira, com todas as implicações que um discurso vazado no modo trágico acarreta. 0 mesmo vale para todos os outros modos de prefiguração poética e expressão narrativa ${ }^{4}$.

$4 \quad$ White (2008) define os quatro modos de consciência histórica em consequência das estratégias prefigurativas que informa cada um deles, referidas aos quatro tropos da linguagem poética (metáfora, metonímia, sinédoque e ironia). Não há necessidade de nos aprofundarmos nos meandros de sua análise dos elementos trópicos contidos na consciência histórica e na historiografia europeia do século XIX; para os nossos propósitos, basta observar sua crítica ao discurso histórico, extraindo lições cuja validade possa ser estendida ao trabalho jornalístico. 
Histórias são criadas das crônicas dos fatos por meio da operação de urdidura de enredo, em que "os acontecimentos são convertidos em estória pela supressão ou subordinação de alguns deles e pelo realce de outros, por caracterização, repetição do motivo, variação do tom e do ponto de vista, estratégias descritivas alternativas e assim por diante" (White, 2001, p. 100; grifo nosso). Trata-se, como já deve ter ficado claro, de expedientes que esperaríamos encontrar na construção de enredo em romances. Vista deste ângulo, "a história não é menos uma forma de ficção do que o romance é uma forma de representação histórica" (White, 2001, p. 138) - e aqui não há nenhuma boa razão que nos impeça de esticar a validade do argumento para o discurso jornalístico.

Os romancistas podiam lidar apenas com eventos imaginários enquanto os historiadores se ocupavam dos reais, mas o processo de fundir os eventos, fossem imaginários ou reais, numa totalidade compreensível capaz de servir de objeto de uma representação é um processo poético. Aqui, os historiadores devem usar as mesmas estratégias tropológicas, as mesmas modalidades de representação das relações em palavras, que o poeta ou o romancista utiliza. No registro histórico não-processado e na crônica dos eventos que o historiador extrai do registro, os fatos existem apenas como um amálgama de fragmentos contiguamente relacionados. Estes fragmentos têm de ser agrupados para formar uma totalidade de um tipo particular, e não de um tipo geral. E são agrupados da mesma forma que os romancistas costumam agrupar as fantasias produzidas pela sua imaginação para revelar um mundo ordenado, um cosmo, onde só poderia existir a desordem ou o caos (White, 2001, p. 141).

Não importa tanto se o episódio narrado é real ou imaginado, pois que os procedimentos através dos quais o historiador ou o romancista lhe confere sentido é o mesmo. Por que haveria de ser diferente no jornalismo? Então o discurso jornalístico não apresenta alguns dos elementos da estrutura narrativa do romance, como a eleição de personagens, a ênfase na agência individual, a necessidade da construção de antagonismos e a divisão em "capítulos"? Que nos seja permitida a liberdade de intervir no texto de White, substituindo as referências ao discurso historiográfico pelo jornalismo.

Narrativas [jornalísticas] não são apenas modelos de acontecimentos e processos passados, mas também afirmações metafóricas que sugerem uma relação de similitude entre esses acontecimentos e 
processos e os tipos de estória que convencionalmente utilizamos para conferir aos acontecimentos de nossas vidas significados culturalmente sancionados. Vista de um modo puramente formal, uma narrativa [jornalística] é não só uma reprodução dos acontecimentos relatados, mas também um complexo de símbolos que nos fornece direções para encontrar um ícone da estrutura desses acontecimentos em nossa tradição literária. [...] A narrativa em si não é o ícone; o que ela faz é descrever os acontecimentos contidos no registro histórico de modo a informar ao leitor o que deve ser tomado como ícone dos acontecimentos a fim de torná-los "familiares" a ele. Assim, a narrativa [jornalística] serve de mediadora entre, de um lado, os acontecimentos nela relatados e, de outro, a estrutura de enredo pré-genérica, convencionalmente usada em nossa cultura para dotar de sentido os acontecimentos e situações não-familiares (White, 2001, p. 105; itálicos nosso).

A urdidura de sentido opera tanto no nível substantivo, a significação acrescida a um acontecimento ou sequência de eventos específicos, quanto no nível formal, a repetição padronizada de moldes dentro dos quais histórias podem ser compreendidas, conformando convenções cognitivas socialmente partilhadas. Notícias não apenas informam sobre os fatos do mundo, mas fornecem modelos de apreensão dos fatos que, tornados convencionais, deixam de ser "um tema de discussão para se tornar uma premissa de qualquer conversa" (Schudson, 1999, p. 279). Eis porque narrativas jornalísticas constroem a realidade no processo de representá-la; são, para tomar de empréstimo a formulação de Nelson Goodman (1995), "modos de fazer mundos".

\section{Modos de fazer mundos e o (relativo) problema do relativismo}

Se o jornalismo mais inventa do que representa mundos, conformando um quadro de referência mais amplo dentro do qual as histórias adquirem sentidos particulares, também construídos narrativamente, então parece não haver muitos motivos para conceder a primazia de sua justificação à correspondência com a realidade. Reduzir o peso e a importância da correspondência com a realidade não significa descartá-la por completo, o que implicaria no apagamento das fronteiras entre jornalismo e literatura de ficção, mas colocar em primeiro plano a necessidade de ancorar a validade do discurso jornalístico em outras bases. Para tanto, será necessário observar, desde um ponto de vista pragmático, o que discurso jornalístico está efetivamente fazendo enquanto diz, e procurar outros critérios através dos quais o possamos julgar. 
Há uma distância entre dizer "a facticidade importa" e "a facticidade é o que mais importa", e essa distância se torna mais claramente distinguível se nos perguntarmos mais pelos usos das palavras do que por seus significados. O que os "narrativistas" parecem não ter dado muita atenção, e que os proponentes do jornalismo como espelho da realidade ignoram por completo, é que ao utilizarmos palavras com o propósito de comunicar algo, estamos ao mesmo tempo efetivamente fazendo algo (Austin, 1990). Compreender o significado desta ação levanta o problema de sua intencionalidade e do exame do contexto em que ocorre. Se quisermos decidir pela superioridade de uma ou outra manchete, o critério da correspondência com a realidade não é de muita serventia, pois que

\begin{abstract}
desacordos não podem ser resolvidos por referência a fatos, porque os fatos emergem somente no contexto de um ponto de vista. Seguese, então, que desacordos devem ocorrer somente entre aqueles que possuem (ou são possuídos por) diferentes pontos de vista, e o que está em jogo num desacordo é o direito de especificar o que serão os fatos dali em diante. Desacordos não são resolvidos por fatos, mas os meios através dos quais fatos são resolvidos. (Fish, 1980, p. 338; tradução nossa ${ }^{5}$.
\end{abstract}

Claro está que, para além da correção factual, há outros princípios aos quais jornalistas devem ajustar seu trabalho, como a transparência de fontes e a exigência de fairness, de "ouvir ambos os lados". Mas nada disso resolve o problema que estamos examinando. Fontes contrárias umas às outras podem ambas estar mentindo ou simplesmente equivocadas (Seidenglanz e Sponholz, 2008). Mais ainda, elas podem ser estrategicamente utilizadas como um falso contraponto dentro de uma narrativa que o jornal esteja deliberadamente construindo, e que por isso não pode ser percebido enquanto tal. Novamente, o que importa é a ação concreta que o jornal está desempenhando ao convocar "ambos os lados", e não aquilo que as fontes propriamente dizem. O principal está no contexto, visto que o juízo quanto à correção de tal ação jornalística

$5 \quad$ No original: "... disagreements cannot be resolved by reference to the facts, because the facts emerge only in the context of some point of view. It follows, then, that disagreements must occur between those who hold (or are held by) different points of view, and what is at stake in a disagreement is the right to specify what the facts can hereafter be said to be. Disagreements are not settled by the facts, but are the means by which the facts are settled". 
só pode ser formulado se examinadas as circunstâncias de sua produção e observados os efeitos sobre a conjuntura em que se insere.

Aqui ficam evidentes os limites das propostas avançadas por autores "narrativistas": dizer que o relato jornalístico é "um jogo de linguagem situado entre a narrativa da história (realista) e a literária (imaginativa)" (Motta, 2005b, p. 10), mas insistir em julgar a validade do relato menos pelos mundos que ele convida o leitor a imaginar como reais do que pelo grau de realismo do mundo supostamente descrito, é, ao fim e ao cabo, permanecer preso ao paradigma do jornalismo como espelho da realidade. Ultrapassá-lo exige uma mudança temporal na localização do critério de validade do discurso jornalístico. $O$ paradigma do espelho ancora o juízo acerca da validade da notícia em referência ao acontecido, o que pressupõe uma finalidade ilocucionária exclusivamente assertiva (Searl, 2000) de manchetes e reportagens. Ora, se não há como separar objetivamente o que pertence ao fato e o que lhe acrescentamos nas tentativas de descrevê-lo, posto que não temos como nos projetarmos para fora de nossas próprias mentes de modo a ocuparmos um ponto arquimediano entre a linguagem e a realidade; se, portanto, reconhecemos a impossibilidade de "retalhar a realidade nas juntas", no local exato onde acaba o evento-em-si e começa a nossa maneira de falar sobre ele (Rorty, 2007), então a medição do valor de um artefato verbal que tem por base a suposta facticidade de seu conteúdo proposicional é, mais do que temerária, necessariamente incompleta, fugidia. A alternativa, se é que desejamos abandonar o monopólio da objetividade como virtude máxima do jornalismo, parte do reconhecimento das múltiplas e coexistentes finalidades ilocucionária do discurso jornalístico (assertiva, diretiva, compromissiva e de declaração) e seus atos perlocucionários, para então procurar um critério de validade no esforço de imaginação crítica acerca dos mundos que esse discurso ajuda a construir.

Mas, afirmar que a correspondência com a realidade importa menos que a intencionalidade e os efeitos reais da narrativa é abrir o flanco para a acusação de relativismo. Esta a provável razão pela qual os "narrativistas" se recusaram a dar o passo seguinte, evitando reconhecer e realizar todo o alcance de suas formulações. O medo, naturalmente, é o do "vale-tudo" pós-moderno na representação. Borradas as fronteiras que distinguem descrição e narração, fato e valor, objetivo e subjetivo, em que bases poderia o discurso jornalístico reivindicar para si a credibilidade de que depende para se manter? Como se diferenciaria da literatura? Se assim fosse, não estaríamos então condenados a uma guerra de versões, tanto mais suja quanto a disposição dos atores de torcer os eventos de modo a encaixá-los numa visão de mundo previamente dada? 
Os alardeados malefícios do relativismo, conhecemos desde a Grécia antiga - a autorrefutação lógica, o subjetivismo incoerente, o niilismo, a paralisia ética. Tais acusações em geral têm suas raízes mais no dogmatismo do acusador do que no relativismo do acusado. "Todas as definições comuns do relativismo", assinala John Ladd, "são formuladas por adversários do relativismo... São definições absolutistas" (citado por Geertz, 2001, p. 48). Ventilada por atores internos ao campo do jornalismo, a denúncia do suposto caos que se instalaria caso abríssemos mão do critério da objetividade e da verdade como correspondência com a realidade cumpre a função ideológica de lhes salvaguardar o lugar de fala. Então não é próprio do discurso ideológico trabalhar "nos conflitos que procura negociar", amiúde com o objetivo de "reapresentar o problema sob a forma de sua solução potencial?" (Eagleton, 1996, p. 210).

Visto de perto, contudo, este revela-se um falso problema. Na falta de espaço para tratar aqui das inúmeras respostas dadas ao desafio do relativismo, fiquemos com a observação, a esta altura um tanto trivial, de que podemos distinguir entre relativismo em sentido forte ("democracia liberal e nazismo são sustentados por crenças válidas cada qual à sua maneira, sendo impossível afirmar a superioridade intrínseca de um regime sobre outro"), e em sentido fraco ("não dispomos de um princípio universal absolutamente incontroverso sobre o qual poderíamos sustentar nossa crença na superioridade da democracia liberal sobre o nazismo"). Ora, dizer que o critério de validação de uma narrativa jornalística não está unicamente em sua adequação aos fatos, mas em sua capacidade de nos fazer enxergá-los por uma perspectiva mais alargada, que ampliaria nossos horizontes de compreensão, não é incorrer em relativismo forte. A própria identificação de um critério substantivo já o afasta, pois que podemos decidir pela superioridade de uma narrativa sobre outra conflitante. Poder-se-ia retrucar, questionando os critérios que definiriam o que conta como "perspectiva mais alargada" e "ampliação de horizontes de compreensão". A resposta começaria pela assunção de nosso próprio etnocentrismo, a convicção de que tais critérios estariam baseados naquilo que nós hoje consideramos como sendo a "boa vida": o respeito aos direitos fundamentais, a busca por um equilíbrio entre igualdade e liberdade, a promoção da justiça e da paz, e assim por diante.

Longe, portanto, de rejeitar a verdade como ideal regulativo, trata-se de ampliar o horizonte normativo de toda atividade de descrição ou representação de modo a abarcar outras preocupações de cunho ético e político, algumas das quais advindas do próprio compromisso de buscar a verdade. Nessa perspectiva, o critério para decidir sobre a qualidade da práxis jornalística não será o grau 
de objetividade dos relatos que produz, seja lá o que isso signifique, mas sim a que desígnios servem as narrativas construídas a partir de tais relatos, os possíveis que deixam entrever, os horizontes que descortinam. E aqui também a mensuração de méritos e falhas se dá por comparação. "Se toda estória plenamente realizada [...] é um tipo de alegoria, aponta para uma moral ou dota os eventos - sejam reais ou imaginários - de uma significância que eles não possuem enquanto mera sequência", diz Hayden White, "então parece possível concluir que toda narrativa histórica tem como propósito latente ou manifesto o desejo de moralizar os eventos de que trata" (White, s/d/p, p. 18; grifo nosso). A questão da validade do discurso jornalístico poderia, então, ser recolocada de modo a nos levar pensar sobre o quão instrutiva é a história que conta, o quanto nos permitiria compreender sobre nós mesmos, e se abriria uma fértil perspectiva acerca dos eventos que descreve. Não se pode pedir mais que isso a uma narrativa.

\section{Referências Bibliográficas}

ALBUQUERQUE, Afonso; LYCARIÃO, Diógenes e MAGALHÃES, Eleonora. Jornalismo parcial feito para vender: a decadência do padrão "catch-all" pelas leis do mercado. Artigo apresentado no VII Congresso da Compolítica. Rio de Janeiro, PUC, 2015.

AUSTIN, John L. Quando dizer é fazer. Porto Alegre: Artes Médicas, 1990.

BOUDANA, Sandrine. A definition of journalistic objectivity as a performance. Media, Culture \& Society. United States: New York. v. 33, n. 3, p. 385-398, April 2011.

BOURDIEU, Pierre. Sobre a televisão. Rio de Janeiro: Zahar, 1997.

BREED, Warren. Controlo social na redação: uma análise funcional. In: TRAQUINA, Nelson (org.). Jornalismo: Questões, Teorias e "estórias". Portugal: Vega, p.152-166, 1999.

BIRD, Elizabeth e DARDENNE, Robert. Mito, Registo e Estórias: Explorando as Qualidades Narrativas das Notícias. In: TRAQUINA, Nelson (org.). Jornalismo: Questões, Teorias e "estórias". Portugal: Vega, p. 263-277, 1999.

CALCUTT, Andrew e HAMMOND, Philip. Journalism Studies - A Critical Introduction. London/New York: Routledge, 2011.

CHOMSKI, Noam. Controle da Mídia. Os espetaculares feitos da propaganda. Rio de Janeiro: Graphia, 2003. 
COELHO, Marcelo. Fatos, argumentos, versões: a política da notícia. In: NOVAES, Adauto (org.) O esquecimento da política. Rio de Janeiro: Agir, p. 335-354, 2007.

DEUZE, Mark. What is journalism? Journalism. England: London, v. 6, n. 4, p. 442-464, 2005.

DURHAM, Meenakshi Gigi. On the relevance of standpoint epistemology to the practice of journalism: the case for "Strong objectivity". Communication Theory, v. 8, n. 2, p. 117-140, May, 1998.

EAGLETON, Terry. A ideologia e suas vicissitudes no marxismo ocidental. In: ZIZEK, Slavoj (org.). Um Mapa da Ideologia. Rio de Janeiro: Contraponto, p. 179-226, 1996.

FISH, Stanley. Is there a text in this class? The authority of interpretative communities. United States: Cambridge, MA Cambridge, MA, Harvard University Press, 1980.

GANS, H. Deciding what's news. A study of CBS evening News, Newsweek and Time. New York: Pantheon, 1979.

GEERTZ, Clifford. Nova Luz sobre a Antropologia. Rio de Janeiro: Jorge Zahar Editor, 2001.

GOODMAN, Nelson. Modos de Fazer Mundos. Portugal: Edições ASA, 1995.

HABERMAS, Jürgen. Direito e Democracia. Entre facticidade e validade. Rio de Janeiro: Tempo Brasileiro, 1997.

HUTCHEON, Linda. Poética do pós-modernismo: história, teoria, ficção. Rio de Janeiro: Imago, 1991.

KUYPERS, Jim A. Framing analysis from a rethorical perspective. In: D'ANGELO, Paul e KUYPERS, Jim A. (eds.) Doing News Framing Analysis. New York/London: Routledge, p. 286-311, 2010.

LICHTENBERG, Judith. In Defense of Objectivity. In: CURRAN, James e GUREVITCH, Michael (eds.). Mass Media and Society. London: Arnold, p. 225-242, 1991.

MCCOMBS, Maxwell. Setting the Agenda. The mass media and public opinion. United Kingdom: Polity Press, 2004.

MIGUEL, Luis Felipe. Quanto vale uma valência? (o paper proibidão). Paper apresentado no VII Congresso da Compolítica. Rio de Janeiro, PUC, 2015.

MOTTA, Luiz Gonzaga. Jornalismo e configuração narrativa da história do presente. Contracampo, Universidade Federal Fluminense, n. 12, p.23-50, $2005 \mathrm{a}$.

. A Análise Pragmática da Narrativa Jornalística. 28 Congresso Brasileiro de Ciências da Comunicação. São Paulo: Intercom, 2005b. Disponível em: < http:// 
www.portcom.intercom.org.br/navegacaoDetalhe.php?id=43427>. Acesso em: 2 fev. 2015.

. The opposition between mediacentric and sociocentric paradigms. Brazilian Journalism Research, v. 1, n. 1, p. 61-86, $2005 c$.

MOULLIAUD, Maurice. A informação ou a parte da sombra. In: MOULLIAUD, Maurice e PORTO, Sergio Dayrell (orgs.). O Jornal: da forma ao sentido. Brasília: Editora Universidade de Brasília, p. 55-65, 2012.

OGNIANOVA, E. e ENDERSBY, J. Objectivity revisited: a spatial model of political ideology and mass communication. Journalism and Mass Communication Monographs, 159 (October), 1996.

PATTERSON, Thomas E. Out of order. New York: Vintage Books, 1993.

RANCIÈRE, Jacques. A partilha do sensível. Estética e Política. São Paulo: Editora 34, 2009.

RODRIGUES, Adriano Duarte. Delimitação, natureza e funções do discurso midiático. In: MOULLIAUD, Maurice e PORTO, Sergio Dayrell (orgs.). O Jornal: da forma ao sentido. Brasília: Editora Universidade de Brasília, p. 227-242, 2012.

RORTY, Richard. Contingência, Ironia e Solidariedade. São Paulo: Martins Fontes, 2007.

A filosofia e o espelho da natureza. Rio de Janeiro: Relume-Dumará, 1994.

SANCHEZ, J. F. El periodista como contador de histórias. Estudos de Periodística. Madrid: Universidad Complutense,1992.

SCHUDSON, Michael. A política da forma narrativa: a emergência de convenções noticiosas na imprensa e na televisão. In:TRAQUINA, Nelson (org.). Jornalismo: Questões, Teorias e “estórias". Portugal: Vega, p. 294-305, 1999.

SEARL, John. Mente, Linguagem e Sociedade. Filosofia no mundo real. Rio de Janeiro: Rocco, 2000.

SEIDENGLANZ, Rene e SPONHOLZ, Liriam. Objetividade e credibilidade midiática. Considerações sobre uma suposta relação. Revista de Comunicação e Cultura. Bahia: Salvador, n. 6, v. 2, p. 1-24, 2008.

SELLARS, Wilfrid. Empirismo e Filosofia da Mente. Rio de Janeiro: Vozes, 2008.

SILVA, Luiz Martins. Imprensa, discurso e interatividade. In: MOULLIAUD, Maurice e PORTO, Sergio Dayrell (orgs.). O Jornal: da forma ao sentido. Brasília: Editora Universidade de Brasília, p. 341-358, 2012.

TRAQUINA, Nelson. Teorias do Jornalismo. Volume 1. Porque as notícias são como 
são. Florianópolis: Editora Insular, 2012.

TUCHMAN, Gaye. Contando Histórias. In: TRAQUINA, Nelson (org.). Jornalismo: Questões, Teorias e "estórias". Portugal: Vega, p. 258-262, 1999.

. Objectivity as Strategic Ritual: An Examination of Newsmen's Notions of Objectivity. American Journal of Sociology, v. 77, n. 4, p. 660-679, 1972.

VEYNE, Paul. Comment on écrit I'histoire. Paris: Seuil, 1971.

WHITE, David M. O Gatekeeper: uma análise de casos na seleção de notícias. In: TRAQUINA, Nelson (org.). Jornalismo: Questões, Teorias e"estórias". Portugal: Vega, 1999.

WHITE, Hayden. Meta-História. A imaginação histórica do século XIX. São Paulo: Editora da Universidade de São Paulo, 2008.

. O valor da narrativa na representação da realidade. In: Caderno de Letras. Universidade Federal Fluminense, n. 3, p. 5-33, s/d/p.

Trópicos do Discurso. Ensaios Sobre a Crítica da Cultura. São Paulo: EDUSP, 2001.

WOLF, Mauro. Teorias da comunicação de massa. São Paulo: Presença, 1990. 